PAPER

\title{
Deficient saccadic inhibition in Asperger's disorder and the social-emotional processing disorder
}

\author{
D S Manoach, K A Lindgren, J J S Barton
}

J Neurol Neurosurg Psychiatry 2004;75:1719-1726. doi: 10.1136/jnnp.2003.025981

See end of article for authors' affiliations ....................

Correspondence to: Dara S Manoach, Massachusetts General Hospital, Charlestown Navy Yard, 36 First Avenue, Room 420, Boston, MA 02129, USA dara@nmr.mgh.harvard. edu

Received 15 August 2003 Revised 9 February 2004 Accepted

18 February 2004

\begin{abstract}
Background: Both Asperger's disorder and the social-emotional processing disorder (SEPD), a form of non-verbal learning disability, are associated with executive function deficits. SEPD has been shown to be associated with deficient saccadic inhibition.

Objective: To study two executive functions in Asperger's disorder and SEPD, inhibition and task switching, using a single saccadic paradigm.

Methods: 22 control subjects and 27 subjects with developmental social processing disorders-SEPD, Asperger's disorder, or both syndromes-performed random sequences of prosaccades and antisaccades. This design resulted in four trial types, prosaccades and antisaccades, that were either repeated or switched. The design allowed the performance costs of inhibition and task switching to be isolated. Results: Subjects with both Asperger's disorder and SEPD showed deficient inhibition, as indicated by increased antisaccade errors and a disproportionate increase in latency for antisaccades relative to prosaccades. In contrast, task switching error and latency costs were normal and unrelated to the costs of inhibition.

Conclusions: This study replicates the finding of deficient saccadic inhibition in SEPD, extends it to Asperger's disorder, and implicates prefrontal cortex dysfunction in these syndromes. The finding of intact task switching shows that executive function deficits in Asperger's disorder and SEPD are selective and suggests that inhibition and task switching are mediated by distinct neural networks.
\end{abstract}

E xecutive functions play a critical role in adaptive human behaviour. They include planning, inhibition, working memory, set maintenance, and flexibility of thought and action. On a purely descriptive level, many cardinal features of developmental disorders that affect social processing, such as Asperger's disorder, can be seen to reflect deficient executive function. Asperger's disorder is characterised by inflexible behaviour, rigid adherence to routines, narrow interests, stereotyped behaviours, and difficulty in inhibiting responses. ${ }^{12}$ Individuals with Asperger's disorder perseverate, have difficulty in establishing a cognitive set, demonstrate poor planning, and have spatial working memory deficits. ${ }^{1-5}$ Deficient executive function may also contribute to deficient theory of mind. ${ }^{2}$ Theory of mind involves internally representing and acting upon the mental states of others, using inhibitory processes to guide responses. ${ }^{1}$ These observations suggest that executive function deficits contribute to the defining social and behavioural features of Asperger's disorder.

In the present study we investigated two different executive functions-inhibition and task switching-in Asperger's disorder and the social-emotional processing disorder (SEPD), a form of non-verbal learning disability. Inhibition is the ability to suppress prepotent responses. Task switching refers to moving flexibly from one behaviour to another in response to changing environmental contingencies. We designed a paradigm that measured task switching and inhibition during identical saccadic tasks. Subjects undertook prosaccade and antisaccade trials. Prosaccade trials required subjects to look towards a suddenly appearing target; antisaccade trials required them to look in the opposite direction. While prosaccades are a relatively automatic response, antisaccades require the inhibition of the prosaccade and the generation of the novel behaviour of looking away from a target. ${ }^{6}$ We presented prosaccade and antisaccade trials in a randomly mixed sequence. This random sequence of trials required subjects to either switch between tasks or to repeat the previous task. As both executive functions were measured during a single paradigm, the stimuli and required motor responses were identical and the demands of other functions, such as sustained attention and working memory, were equal.

Saccadic eye movements during these tasks provide objective measures of inhibition and task switching. They use a control system with relatively well delineated neuroanatomy and thereby allow us to examine the integrity of specific neural systems in individuals with Asperger's disorder and SEPD. We previously reported deficient saccadic inhibition in SEPD. ${ }^{7}$ Based on earlier findings in autism and high functioning autism, ${ }^{89}$ we hypothesised that individuals with Asperger's disorder would also show deficient saccadic inhibition. In addition, we wanted to determine whether these groups have task switching deficits, given their perseverative behaviour. Finally, we examined the relations between inhibition and task switching measures. Correlated deficiencies would be consistent with a single dysfunctional control system mediating both executive functions. In contrast, selectively impaired and uncorrelated performance would suggest separate executive control systems.

The variety of labels applied to developmental conditions that affect social processing reflects a lack of consensus regarding their diagnosis and the different approaches applied to describe them. SEPD is described in the neurological literature and is thought to arise from congenital or early acquired damage to the right hemisphere. ${ }^{10-13}$ It has also been referred to as right hemisphere learning disability ${ }^{11}$ and is quite similar to non-verbal learning disability, which is defined by largely overlapping criteria. ${ }^{14-16}$ These disorders do

Abbreviations: SEPD, social-emotional processing disorder; SPD, social processing disorder 
not appear in the Diagnostic and Statistical Manual of Mental Disorders (DSM). Asperger's disorder, in contrast, is described primarily in the psychiatric literature and first appeared in the DSM in 1994 (DSM-IV). ${ }^{17}$

The DSM-IV criteria for Asperger's disorder overlap with the criteria for SEPD. The defining feature of both disorders is a developmental history of deficient interpersonal relations. Both diagnoses also require normal language acquisition and development. The primary distinctions between Asperger's disorder and SEPD are the Asperger's disorder criterion of restricted, repetitive, and stereotyped patterns of behaviour, interests, and activities, and the SEPD criterion of a neuropsychological profile implicating the right hemisphere. SEPD has been associated with right hemisphere dysfunction on the basis of clinical neurodiagnostic studies (for example, electroencephalography and magnetic resonance imaging). ${ }^{13}{ }^{18}$ Published reports are inconclusive as to whether Asperger's disorder is also characterised by a right hemisphere implicating neuropsychological profile. ${ }^{19-22}$

The considerable phenomenological overlap between Asperger's disorder and SEPD has led to a debate about whether or not these syndromes represent distinct entities. ${ }^{19}{ }^{21-23}$ More valid diagnosis will be facilitated by understanding their neural bases and determining whether current diagnostic distinctions have external validity. In other words, do the diagnostic distinctions predict outcome on measures that are independent of diagnosis? Executive function deficits are independent of the diagnosis of Asperger's disorder and SEPD, but are key associated features ${ }^{1357}$ which may contribute to defining social and behavioural symptoms. ${ }^{3}$ A secondary goal of this study was to compare executive function in the Asperger's disorder and SEPD samples. We expected to replicate our finding of deficient saccadic inhibition in $\mathrm{SEPD}^{7}$ and to extend it to Asperger's disorder.

\section{METHODS \\ Diagnosis of subjects with developmental social processing disorders}

The subjects of the present investigation met criteria for Asperger's disorder, SEPD, or both disorders. We will refer to these groups in aggregate as the social processing disorder (SPD) group. SPD subjects, aged 16 and over, were recruited from adult outpatient clinics offering neuropsychological assessment in the Boston area. We limited our sample to age 16 and over, because saccadic inhibition does not develop fully until late adolescence. ${ }^{24}{ }^{25}$ The initial SPD diagnosis was made by the referring neuropsychologist. A second licensed neuropsychologist (DSM), blind to study outcome, made a research diagnosis based on a thorough review of medical records, interviews with the subject and-whenever possible-a parental or immediate family informant, and behavioural observations. We obtained detailed histories with attention to birth related events, developmental milestones, emotional adjustment, and social and family history. Behavioural observations of paralinguistic communication ability-including the use of eye contact, facial expression, and gesture-were recorded.

Diagnostic criteria are enumerated in table 1. The diagnosis of Asperger's disorder was based on DSM-IV criteria. All subjects had at least average verbal intellect (verbal IQ $\geqslant 90$ ) and histories of normal language acquisition defined as the use of single words by the age of two years and communicative phrases by the age of three. SEPD subjects were required to have right hemisphere implicating neuropsychological profiles, operationally defined as verbal IQ greater than performance IQ by 10 points or more (a 10 point discrepancy is significant at the $0.05 \% \operatorname{level}^{26}$ ). Subjects were excluded if they had histories of acquired brain disease or
Table 1 Diagnostic criteria for developmental social processing disorder subgroups

\begin{tabular}{|c|c|c|c|}
\hline Criterion & $\begin{array}{l}\text { Asperger's } \\
\text { disorder }(n=4)\end{array}$ & $\begin{array}{l}\text { SEPD } \\
(n=11)\end{array}$ & $\begin{array}{l}\text { Both } \\
(n=12)\end{array}$ \\
\hline Social impairment & + & + & + \\
\hline Repetitive behaviour & + & - & + \\
\hline $\begin{array}{l}\text { Significant impairment in } \\
\text { function }\end{array}$ & + & + & + \\
\hline Normal language acquisition & + & + & + \\
\hline $\begin{array}{l}\text { No clinically significant } \\
\text { general delay in cognitive }\end{array}$ & & & \\
\hline development & + & + & + \\
\hline No autism, PDD, or & & & \\
\hline schizophrenia & + & + & + \\
\hline Right hemisphere dysfunction & - & + & + \\
\hline
\end{tabular}

significant brain injury after the age of five. Healthy control subjects, without a history of psychiatric or neurological illness, were recruited from the community by poster advertisements.

All subjects were screened to exclude substance abuse or dependence within the past six months and any independent conditions that might affect brain function. Two SPD and four control subjects did not complete the protocol. The final sample size was 27 SPD subjects and 22 controls (table 2). Of the 27 SPD subjects, four met criteria for Asperger's disorder alone, 11 met criteria for SEPD alone, and 12 met criteria for both Asperger's disorder and SEPD (BOTH).

Nineteen SPD subjects were on drug treatment, primarily for mood disorders (for example, depression, dysthymia) or attention deficits. Twenty SPD and 16 control subjects were strongly right handed, as determined by a laterality score of 70 or above on the modified Edinburgh handedness inventory. ${ }^{27}$ The control and SPD groups did not differ in age, sex, handedness, estimated verbal IQ based on a test of single word reading, ${ }^{28}$ or parental socioeconomic status. ${ }^{29}$ Control subjects showed a trend to more years of education.

The study was approved by the committee on clinical investigations at Beth Israel Deaconess Medical Center. All subjects gave written informed consent after the experimental procedures had been fully explained, according to the Declaration of Helsinki.

\section{Supplemental neuropsychological assessment of SPD subjects}

All SPD subjects had undergone neuropsychological evaluations for clinical purposes, and supplemental measures were administered as necessary to characterise and compare SPD subgroups (table 3). As IQ scores contributed to SPD subgroup diagnosis, it is not surprising that subjects with Asperger's disorder had lower verbal and higher performance IQs on the Wechsler adult intelligence scale-revised or third edition. ${ }^{26}{ }^{30}$ The subgroups did not differ significantly in performance of the logical memory or visual reproduction subtests of the Wechsler memory scale (revised or third edition $\left.^{31}{ }^{32}\right)$. Although not statistically significant, the SEPD and BOTH subgroups recalled stories better than visual figures. All subgroups recognised words better than faces on the recognition memory test. ${ }^{33}$ The subgroups did not differ in academic achievement (wide range achievement test-revised or third edition ${ }^{34}{ }^{35}$ ) and performed better on tests of single word reading and spelling than arithmetic. The subgroups were not impaired and did not differ in the visual discrimination of faces (facial recognition test ${ }^{36}$ ) or in judgement of line orientation. ${ }^{37}$ On the grooved pegboard, ${ }^{38}$ SEPD subjects showed a tendency to perform more slowly 
Table 2 Demographic data and rating scale scores

\begin{tabular}{|c|c|c|c|c|}
\hline Subject characteristics & $\begin{array}{l}\text { Healthy subjects } \\
\text { (n=22) }\end{array}$ & $\begin{array}{l}\text { SPD subjects } \\
(\mathrm{n}=27)\end{array}$ & $t$ Value & p Value \\
\hline Age & $34.6(11.2)$ & $34.4(11.2)$ & 0.03 & 0.98 \\
\hline Sex & $11 \mathrm{M} / 11 \mathrm{~F}$ & $17 \mathrm{M} / 10 \mathrm{~F}$ & $\phi=0.13 \dagger$ & 0.40 \\
\hline Laterality score (handedness) & $70.2(50.4)$ & $68.2(51.2)$ & 0.14 & 0.89 \\
\hline Education (years) & $17.4(4.1)$ & $15.3(3.4)$ & 1.88 & $0.07^{*}$ \\
\hline Estimated verbal IQ & $108.5(13.2)$ & $111.1(7.9)$ & 0.86 & 0.39 \\
\hline Parental SES $\ddagger$ & $1.7(1.1)$ & $1.9(1.1)$ & $z=0.61 \dagger$ & 0.54 \\
\hline \multicolumn{5}{|c|}{$\begin{array}{l}\text { Values are mean (SD). } \\
\text { ‘ } \$ 10 \text {. } \\
\text { †The } \phi \text { value is the result of a Fisher's exact test. The } z \text { value is the result of a non-parametric Mann-Whitney } U \text { test } \\
\text { comparison. } \\
\text { †A lower score denotes higher status. } \\
\text { SPD, social processing disorder; SES, socioeconomic status. }\end{array}$} \\
\hline
\end{tabular}

than Asperger's disorder subjects with the left hand. Mean scores on the Beck depression inventory- $\mathrm{II}^{39}$ were in the minimal range.

\section{Eye movement apparatus and protocol}

We recorded eye movements with a magnetic search coil technique, using a scleral contact lens and a three foot field coil (Crist Instruments, Bethesda, Maryland, USA). The subject's head was secured in a chin rest, with the cornea $81 \mathrm{~cm}$ away from a tangent screen. Displays were generated by a Power Macintosh 9600/233, using programs written in $\mathrm{C}++$ on the Vision Shell programming platform (www.kagi. com/visionshell), and back projected with an Eiki LC-7000U LCD projector. The lens was placed in the left eye. The system was calibrated by having the subject sequentially fixate nine targets in a square grid spanning $50^{\circ}$. Twelve data points were collected at each of the target locations, and a regression method was used to find the best linear fit. Eye position was digitised at 500 samples/s. A five point central difference algorithm ${ }^{40}$ was used to derive velocity from eye position. The saccadic tasks are described in fig 1 .
Before testing, subjects were informed that they would receive a monetary bonus for each correct response. Subjects practiced with each of three different block types: prosaccade only, antisaccade only, and mixed task blocks. The single task blocks had 26 trials. The mixed task blocks consisted of 52 trials of prosaccades and antisaccades presented in random order. Each block type was repeated four times in a counterbalanced order to mitigate the effects of learning and fatigue. All subjects began with a single task block (half began with prosaccades, half with antisaccades), followed by the other type of single task block, followed by a mixed task block. The order of the three block types was then reversed. The entire sequence of six blocks was repeated for a total of 12 blocks. This generated about 104 trials of each of six trial types: blocked (from single task blocks) and repeated and switched trials (for example, preceded by the same trial type or not) of both prosaccades and antisaccades.

We were primarily interested in the mixed task blocks as they provide measurements of both inhibition and task switching. However, because most studies present prosaccade and antisaccade trials in single task blocks, we first compared

Table 3 Comparisons of the social processing disorder subgroups on neuropsychological test scores

\begin{tabular}{|c|c|c|c|c|c|}
\hline \multicolumn{2}{|l|}{ Test } & \multirow{3}{*}{$\begin{array}{l}\begin{array}{l}\text { Asperger's disorder } \\
(\mathbf{n}=4)\end{array} \\
106.8(16.4)^{* *} \\
111.5(14.5)^{*}\end{array}$} & \multirow{3}{*}{$\begin{array}{l}\text { SEPD }(\mathbf{n}=11) \\
122.1(8.8) \\
95.2(8.9)\end{array}$} & \multirow{3}{*}{$\begin{array}{l}\text { Both syndromes } \\
(n=12)\end{array}$} & \multirow{3}{*}{$\begin{array}{l}\text { p Value } \\
\text { IQ by subgroup: } 0.0002^{*}\end{array}$} \\
\hline WAIS & Verbal IQ & & & & \\
\hline & Performance IQ & & & & \\
\hline \multirow[t]{4}{*}{ WMS centile } & LM I & $40.0(47.8)$ & $65.4(28.6)$ & $52.1(25.1)$ & Subgroup: 0.80 \\
\hline & LM II & $61.0(35.0)$ & $68.9(25.8)$ & $56.6(30.2)$ & Subtest (LM $\vee$ VR): 0.41 \\
\hline & VR I & $58.7(50.1)$ & $52.6(40.2)$ & $25.3(25.6)$ & Subgroup by subtest: 0.60 \\
\hline & VR II & $58.3(37.0)$ & $48.1(37.6)$ & $48.8(25.6)$ & \\
\hline \multirow[t]{4}{*}{ RMT $(\max =50)$} & Words & $49.5(1.0)$ & $47.7(2.9)$ & $48.8(2.2)$ & Subgroup: 0.33 \\
\hline & Words (centile) & $>75$ & 68 & $>75$ & \\
\hline & Faces & $43.5(3.9)$ & $40.4(6.1)$ & $42.1(5.0)$ & Subtest (word $v$ face): $<0.0001^{*}$ \\
\hline & Faces (centile) & 54 & 21 & 39 & Subgroup by subtest: 0.91 \\
\hline \multirow[t]{3}{*}{ WRAT centile } & Reading & $58.2(22.9)$ & $70.4(18.7)$ & $76.5(11.9)$ & Subgroup: 0.11 \\
\hline & Spelling & $61.8(26.7)$ & $71.1(17.4)$ & $83.8(7.8)$ & Subtests: $0.0002^{*}$ \\
\hline & Arithmetic & $39.5(8.2)$ & $60.4(12.7)$ & $48.7(33.3)$ & Subgroup by subtest: 0.25 \\
\hline \multicolumn{2}{|l|}{ Benton faces } & 46.7 (2.9) & $44.0(7.5)$ & $45.3(3.5)$ & Subgroup: 0.75 \\
\hline \multirow{2}{*}{\multicolumn{2}{|c|}{ Line orientation }} & $27.0(2.6)$ & $23.6(7.3)$ & $22.4(3.5)$ & Subgroup: 0.44 \\
\hline & & (high average) & (average) & (low average) & \\
\hline \multirow[t]{2}{*}{ Grooved pegt (s) } & Left & $68.0(8.8)^{\star *}$ & $96.0(35.4)$ & $89.3(20.0)$ & Subgroup: 0.22 \\
\hline & Right & $71.3(15.3)$ & $82.0(21.6)$ & $81.8(18.2)$ & Subgroup: 0.60 \\
\hline \multicolumn{2}{|c|}{ Beck depression inventory-II } & $12.0(12.5)$ & $12.5(9.8)$ & $8.9(8.6)$ & Subgroup: 0.66 \\
\hline \multicolumn{6}{|c|}{$\begin{array}{l}\text { Values are mean (SD). } \\
{ }^{*} p \leqslant 0.05 ;{ }^{* *} p \leqslant 0.10 \text { (the } p \text { values are for the appropriate F statistic). } \\
\text { TA lower score denotes faster performance. } \\
\text { IQ, intelligence quotient; LM, logical memory; max, maximum; RMT, recognition memory test; VR, visual reproduction; WAIS, Wechsler adult intelligence scale; } \\
\text { WMS, Wechsler memory scale; WRAT, wide range achievement test; I, immediate recall; II, delayed recall. }\end{array}$} \\
\hline
\end{tabular}




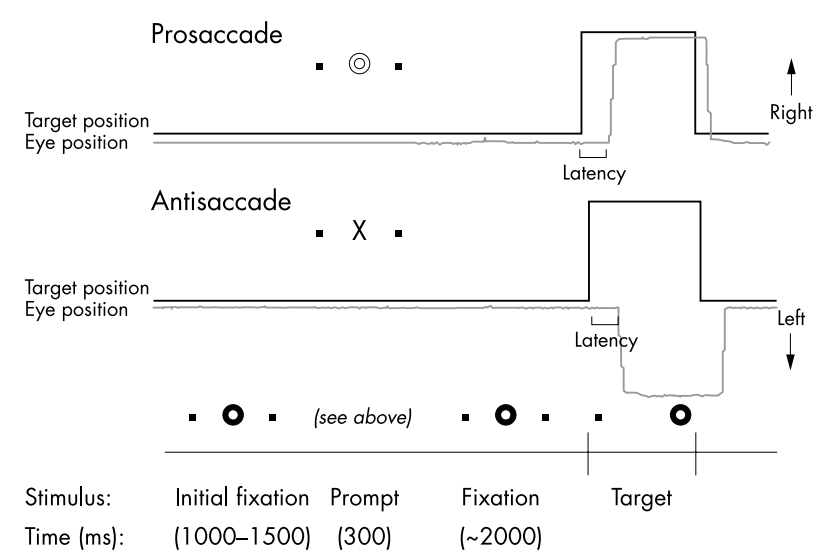

Figure 1 Saccadic tasks. Illustration of target position and eye position during correct performance of the prosaccade and antisaccade tasks. The initial stimulus presentation display consisted of a dark background with a white fixation ring at the centre, of $1.0^{\circ}$ diameter and luminance of $20 \mathrm{~cd} / \mathrm{m}^{2}$. The fixation ring was flanked by two dots of $0.7^{\circ}$ diameter and equal luminance placed $20^{\circ}$ right and left of centre. These two peripheral dots were visible in each trial until obscured by a target. The subject was required to look at the central fixation point, and each trial began when a subject's eye fell within $3^{\circ}$ of the fixation point. After a period randomly varying between 1.0 and $1.5 \mathrm{~s}$, the fixation point was replaced by one of two symbols: a yellow " $\mathrm{O}$ " with a surrounding ring of $4.5^{\circ}$ diameter was the prompt for a prosaccade, and a blue " $\mathrm{X}$ " spanning $4.5^{\circ}$ was the prompt for an antisaccade. Prompts lasted 300 $\mathrm{ms}$ and were then replaced by the white fixation ring. After a mean interval of $2 \mathrm{~s}$, the fixation ring disappeared and a similar ring appeared around one of the two peripheral dots, the side determined randomly. This was the cue for the subject to make their saccade as quickly and accurately as possible. The white ring remained in the peripheral location until either the subject's eye had fallen within $3^{\circ}$ of the desired end position or 10 seconds had elapsed, at which time it returned to the central fixation point for the next trial.

trials from the single task blocks with repeated trials from the mixed task blocks to determine whether the randomised presentation of prosaccade and antisaccade trials resulted in increased errors and latencies. The presentation of trials in mixed task blocks slowed performance marginally but did not affect the number of errors and, more importantly, did not affect the groups differentially. Because the inhibition findings from the single task blocks are replicated in the mixed task blocks, only the analyses or the mixed task blocks are presented.

\section{Scoring of eye movement protocols}

We identified saccades as eye movements with velocities exceeding $46.9 \%$. The onset of a saccade was defined as the point at which the velocity of the eye first exceeded $31.3 \%$, and the end of a saccade was the point where the eye's velocity fell below this baseline. For each saccade, we recorded directional accuracy with respect to the required response and latency from target onset for the directionally correct responses only. The first trial of each block was eliminated from analysis as neither repeated nor switched. We also eliminated trials with saccadic latencies under 100 ms or over $2500 \mathrm{~ms}$ (less than 1\% of total responses).

\section{Data analysis}

Accuracy and latency

We analysed per cent errors with repeated measures analysis of variance (ANOVA) with a group factor (control, SPD), and task (prosaccade, antisaccade) and condition (repeated, switched) as repeated measures. Latencies for correct trials were analysed using randomised block ANOVA with subjects nested within group as the random factor, and group, task,
Table 4 Formulas used to isolate antisaccade and task switching error and latency costs

\begin{tabular}{lll}
\hline & \multicolumn{2}{l}{ Task } \\
\cline { 2 - 3 } Condition & PS & AS \\
\hline Repeated & $\mathrm{PS}_{\mathrm{R}}$ & $\mathrm{AS}_{\mathrm{R}}$ \\
Switched & $\mathrm{PS}_{S}$ & $\mathrm{AS}_{\mathrm{S}}$ \\
\hline
\end{tabular}

Repeated prosaccades $\left(\mathrm{PS}_{\mathrm{R}}\right)$ are the baseline because they require neither an antisaccade nor a task switch. To isolate the antisaccade cost, the baseline was subtracted from repeated antisaccades. To isolate task switching costs, the baseline was subtracted from switched prosaccades. To isolate the task switching cost specifically for antisaccades, repeated antisaccades were subtracted from switched antisaccades.

Antisaccade cost: $A S_{R}-P S_{R}$

Task switch cost for PS: $\mathrm{PS}_{\mathrm{S}}-\mathrm{PS}_{\mathrm{R}}$

Task switch cost for $\mathrm{AS}: \mathrm{AS}_{S}-\mathrm{AS}_{\mathrm{R}}$

$A S_{S}$, switched antisaccade; $A S_{R}$, repeated antisaccade;

$P S_{R}$, repeated prosaccade; $P S_{S}$, switched prosaccade.

and condition as factors. Pairwise comparisons were evaluated with contrasts. We isolated executive function costs by subtracting the baseline performance from other trial types. Repeated prosaccades were used as the baseline because they require neither an antisaccade nor a task switch. The formulas for these costs are given in table 4. Pearson correlation coefficients were used to describe the relations between performance costs.

\section{RESULTS}

\section{Inhibition}

Errors

These results are given in fig 2A. Subjects made more antisaccade than prosaccade errors (task: $F(1,47)=50.60$, $\mathrm{p}<0.0001)$. As predicted, there was a significant group $\times$ task interaction $(F(1,47)=6.79, p=0.01)$. SPD subjects did not differ from control subjects in prosaccade errors $(\mathrm{t}(47)=1.31, \mathrm{p}=0.19)$ but made more antisaccade errors $(\mathrm{t}(47)=4.22, \mathrm{p}<0.0001)$. The mean $(\mathrm{SD})$ antisaccade error rate for SPD subjects $(22(13) \%)$ was almost twice that of control subjects (12 (9)\%). This finding of impaired inhibition was not restricted to a particular SPD subgroup. The similarity of the antisaccade error rates in the SPD subgroups suggested that the failure to find a difference between the subgroups did not reflect decreased power because of small sample sizes (Asperger's disorder: 24 (19)\%; SEPD: 21 (11)\%; BOTH: $22(12) \%)$. In addition, each subgroup made significantly more errors than control subjects (Asperger's disorder: $\mathrm{t}(24)=2.40, \mathrm{p}=0.02 ; \quad$ SEPD: $\mathrm{t}(31)=2.83$, $\mathrm{p}=0.008$; both conditions: $\mathrm{t}(32)=3.07, \mathrm{p}=0.004)$. The SPD subgroups did not differ from one another or from control subjects on prosaccade errors. Drug treated and untreated SPD subgroups showed comparable antisaccade error rates (drug treated: 22 (13)\%; no drug treatment: 20 $(14) \% ; \mathrm{t}(25)=0.44, \mathrm{p}=0.66)$, and both made significantly more errors than control subjects (drug treated: $\mathrm{t}(39)=3.44$, $\mathrm{p}=0.001$; no drug treatment: $\mathrm{t}(28)=2.26, \mathrm{p}=0.03)$.

\section{Latency}

These results are given in fig 2B. Antisaccade latencies were longer than prosaccade latencies (task: $F(1,47)=$ $454.15, \mathrm{p}<0.0001)$. There was a group $\times$ task interaction $(\mathrm{F}(1,47)=15.47, \mathrm{p}<0.0001)$. Although the latencies for SPD subjects did not differ significantly from those of control subjects on either task (prosaccade $\mathrm{t}(47)=0.34, \mathrm{p}=0.74$; antisaccade $\mathrm{t}(47)=0.72, \mathrm{p}=0.47)$, SPD subjects showed a disproportionate relative increase in latency for antisaccades compared with prosaccades (control: 15 (10)\% increase; $\mathrm{t}(21)=12.00, \quad \mathrm{p}=6 \mathrm{e}-33 ; \quad$ SPD: $22 \quad(11) \%$ increase; 
$\mathrm{t}(26)=18.29, \mathrm{p}=2 \mathrm{e}-73)$. For the analysis of SPD subgroups $v$ controls, the group $\times$ task interaction remained significant $(\mathrm{F}(3,45)=7.23, \mathrm{p}<0.0001)$. In addition, each SPD subgroup showed a disproportionate increase in latency for antisaccade $v$ prosaccade trials relative to controls (Asperger's disorder: 29 (9)\% increase; SEPD: 20 (11)\%; BOTH: 21 (11)\%). Drug treated and untreated SPD subjects did not differ in latency $(F(1,25)=0.98, p=0.33)$ for either prosaccades $(\mathrm{t}(25)=0.45, \quad \mathrm{p}=0.66) \quad$ or antisaccades $\quad(\mathrm{t}(25)=1.50$, $\mathrm{p}=0.13)$, suggesting that drugs were not an important factor in our findings.

\section{Task switching}

Errors

These data are shown in fig 3A. There were significantly more errors on switched compared with repeated trials (condition: $\mathrm{F}(1,47)=46.61, \mathrm{p}<0.0001)$, but the groups did not differ in task switching errors (group $\times$ condition: $F(1,47)=0.01$, $\mathrm{p}=0.92)$ or in task switch costs for either prosaccades or antisaccades (prosaccades: $\mathrm{t}(47)=1.08, \mathrm{p}=0.29$; antisaccades: $\mathrm{t}(47)=0.91, \mathrm{p}=0.37$ ) (fig $3 \mathrm{C}$ ). Dividing the SPD sample into subgroups did not affect the findings. In summary, control and SPD subjects showed significant task switching error costs for both prosaccades and antisaccades and did not differ in the magnitude of these costs.

\section{Latency}

These results are given in fig 3B. The main effect of condition (repeated $v$ switched) was not significant $(F(1,47)=0.48$, $\mathrm{p}=0.49)$. This is because task switching affected the latency of prosaccades and antisaccades differently (condition $\times$ task interaction: $F(1,47)=35.99, p<0.0001)$. For prosaccades, switched trials were significantly slower than repeated trials $(\mathrm{t}(47)=4.87, \mathrm{p}<0.0001)$. The opposite was true for antisaccades $(t(47)=3.64, p=0.0003)$. Group did not interact with condition $(\mathrm{F}(1,47)=1.52, \mathrm{p}=0.22)$ or with condition $\times$ task $(F(1,47)=0.001, p=0.98)$. In summary, there were no significant group differences in task switching latency costs (fig 3C). This finding was also true for SPD subgroups.

\section{Relation of inhibition and task switching costs}

The error and latency costs of saccadic inhibition and task switching were not related in either group (errors: control: $r=-0.06, \mathrm{p}=0.79$; SPD: $r=-0.22, \mathrm{p}=0.27$; latency: control: $r=0.29, \mathrm{p}=0.19$; SPD: $r=0.23 \mathrm{p}=0.26)$. In the control group, the error costs of antisaccades $(7(6) \%)$ and task switching $(7(8) \%)$ were approximately equal. In the SPD group, error costs were significantly greater for inhibition (17 (15)\%) than for task switching (9 (6)\%; $t(26)=2.61$, $\mathrm{p}=0.02)$. Latency costs were significantly greater for antisaccades than for task switching in both groups (control: $\mathrm{t}(21)=4.29, \mathrm{p}=0.0003$; SPD: $\mathrm{t}(26)=6.21, \mathrm{p}<0.0001)$.

\section{DISCUSSION}

Subjects with Asperger's disorder, SEPD, and those who met criteria for both disorders showed deficient inhibition on the antisaccade task. They made more errors than control subjects and showed a disproportionate increase in latency for antisaccades relative to prosaccades. Deficient saccadic inhibition has previously been reported in autism, ${ }^{8}$ high

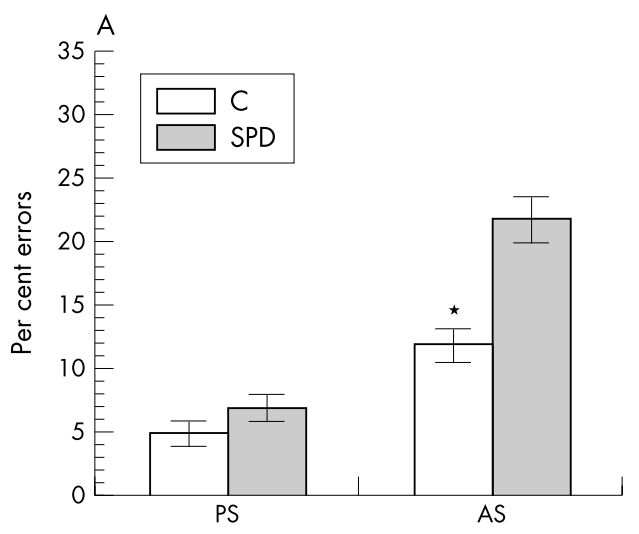

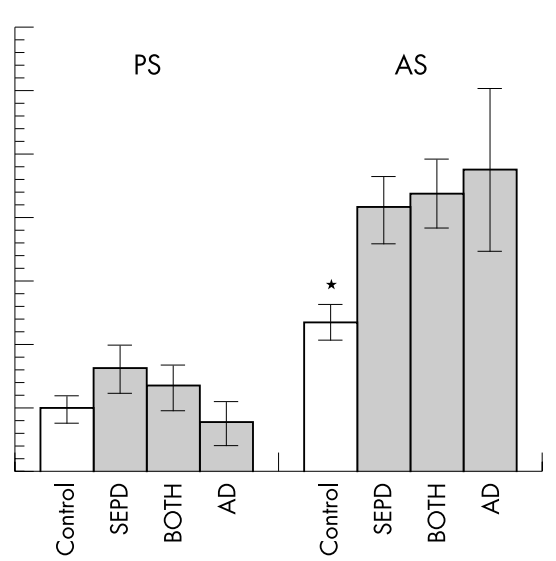

Figure 2 Inhibition: bar graphs with standard error bars for (A) per cent errors and (B) latency for prosaccades and antisaccades. The graphs are collapsed across condition (repeated $v$ switched). On the right, the developmental social processing disorder (SPD) subgroups are graphed separately. An asterisk indicates that the comparison between adjacent bars is significant at $p \leqslant 0.05 . A D$, Asperger's disorder; AS, antisaccade; BOTH, subjects meeting criteria for both syndromes; C, control; PS, prosaccade; SEPD, social-emotional processing disorder.
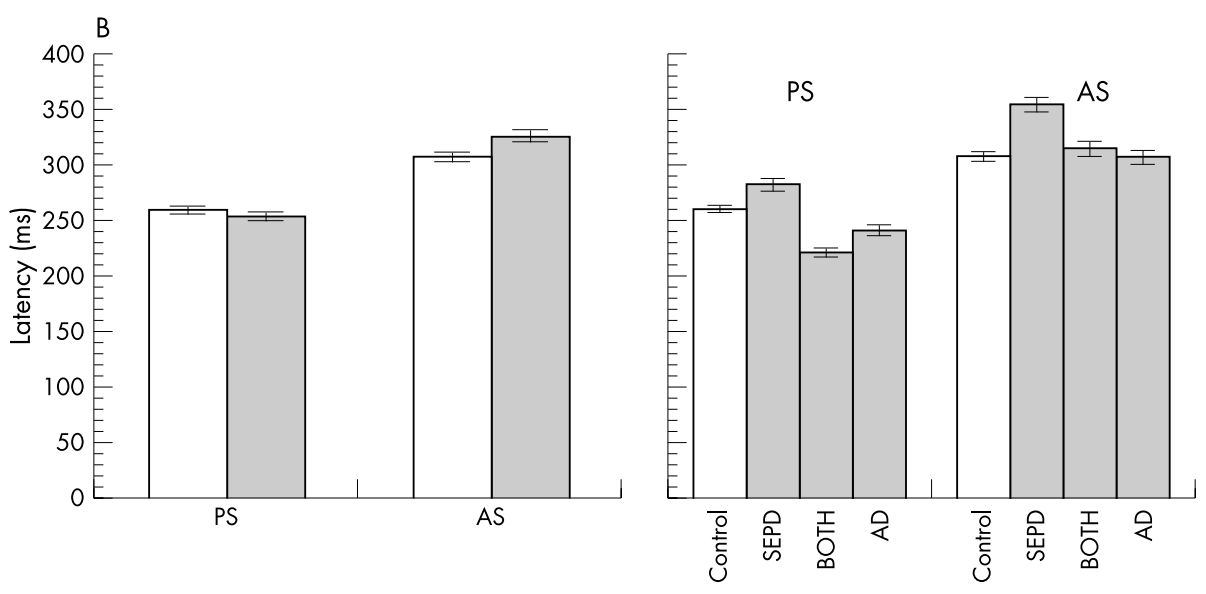

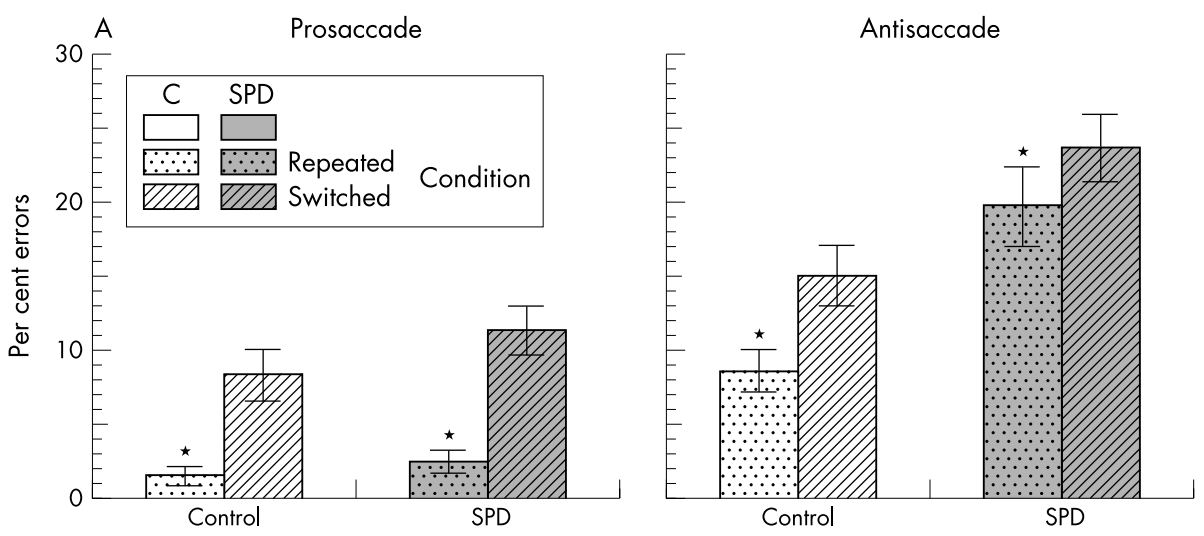

Figure 3 Task switching: bar graphs with standard error bars for $(A)$ per cent errors and (B) latency separated by task (prosaccades: left; antisaccades: right) and by condition (repeated $v$ switched). Isolated task switch costs for prosaccades and antisaccades are graphed in (C) (see formulas in table 4). An asterisk indicates that the comparison between adjacent bars is significant at $p \leqslant 0.05$. AS, antisaccade; C, Control; PS, prosaccade; SPD, social processing disorder.
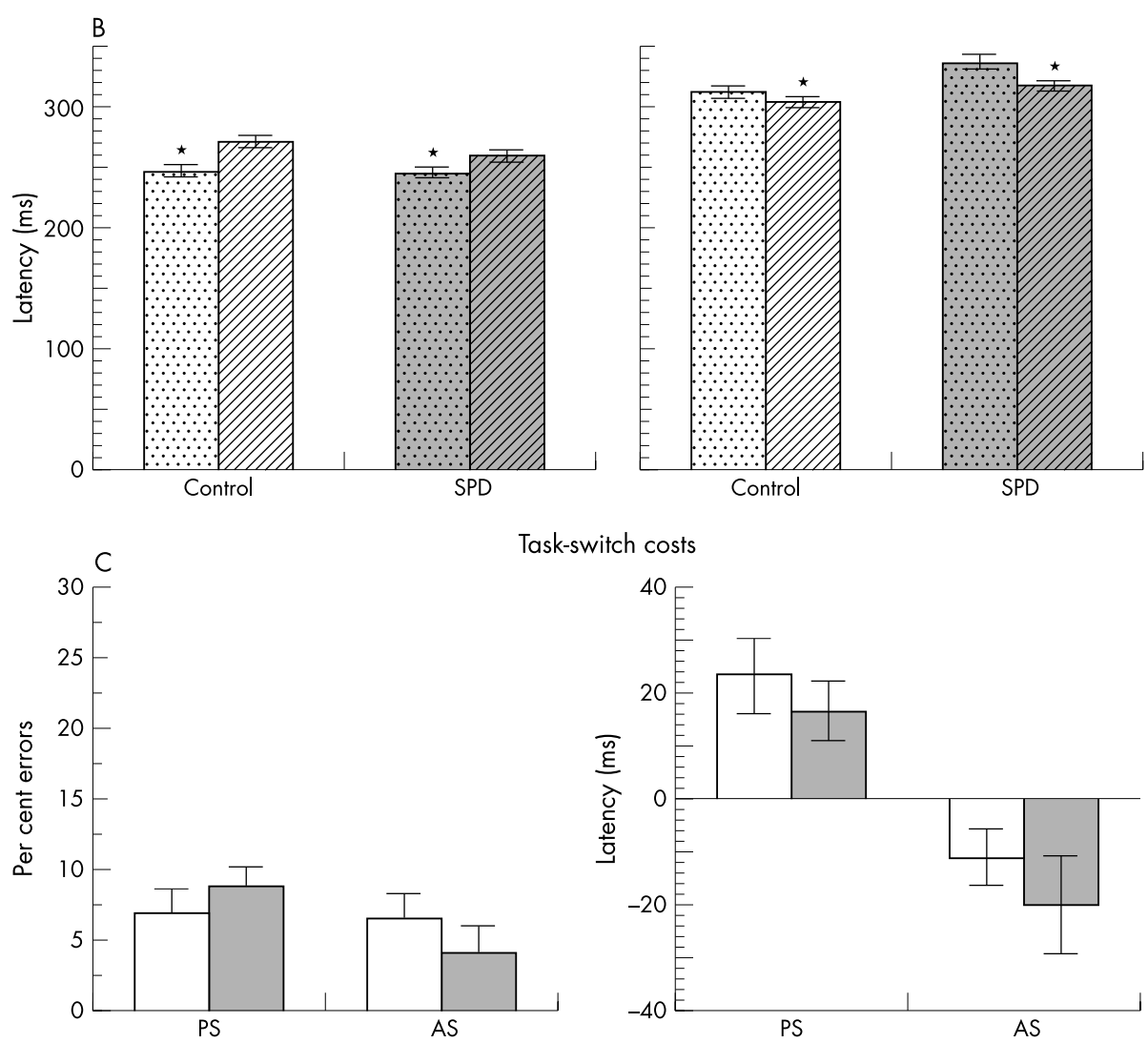

Task-switch costs

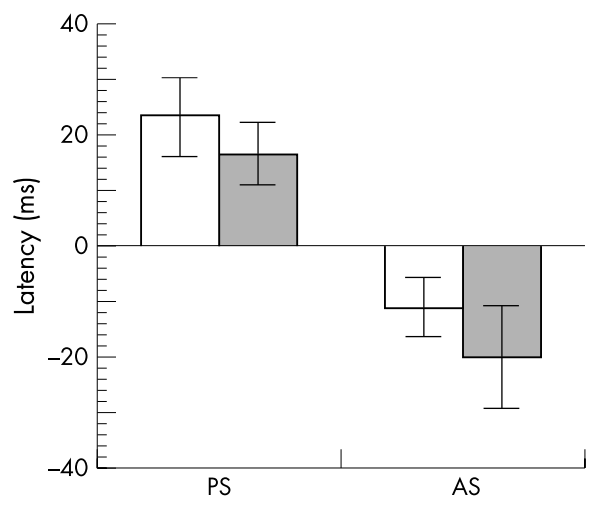

functioning autism, ${ }^{9}$ and SEPD. ${ }^{7}$ This study replicates the finding of deficient saccadic inhibition in SEPD and extends it to Asperger's disorder. In contrast, task switching was intact in Asperger's disorder and SEPD, and the performance costs of inhibition and task switching were not related. This behavioural dissociation shows that executive function deficits in Asperger's disorder and SEPD are selective.

The finding of a selective impairment of inhibition is unlikely to reflect reduced sensitivity of the task switching measurements. In the control group, error costs were equivalent for antisaccades and task switching, and performance was not at ceiling levels. In addition, although latency costs were significantly smaller for task switching than antisaccades, both groups showed similar significant task switching costs, indicating that the measurements were sensitive. Our finding of a selective impairment suggests that inhibition and task switching are mediated by distinct anatomical networks, only one of which is dysfunctional in
Asperger's disorder and SEPD. Because saccadic eye movements use a control system with a relatively well delineated neuroanatomy and physiology, these findings can guide the generation of testable hypotheses regarding dysfunctional neural circuitry in these disorders.

In both Asperger's disorder and SEPD, prosaccade performance was intact but antisaccade performance was deficient. Neuroimaging studies reveal increased activation in many cortical and subcortical areas for antisaccades compared with prosaccades, including the dorsolateral prefrontal cortex in many $y^{41-44}$ but not all studies.$^{45}$ Patients with large frontal lobe excisions $^{46} 47$ and with more circumscribed lesions of the dorsolateral prefrontal cortex, but not of the frontal eye field or supplementary motor area, have saccadic inhibition deficits. ${ }^{4-50}$ A recent EEG study showed that while the same basic neural circuitry supports prosaccade and antisaccade performance, antisaccades are characterised by additional dorsolateral prefrontal cortical activity occurring 160-60 ms 
before saccade generation. ${ }^{51}$ These findings suggest that antisaccade performance relies on activation in a distributed neural network that includes the dorsolateral prefrontal cortex. The finding of deficient saccadic inhibition in Asperger's disorder and SEPD is consistent with other evidence that implicates the prefrontal cortex in these syndromes. This includes findings of increased concentrations of $\mathrm{N}$-acetylaspartate (NAA) in the prefrontal cortex ${ }^{52}$ and reduced grey matter in frontostriatal pathways. ${ }^{53}$

While both Asperger's disorder and SEPD have an early onset, saccadic inhibition does not develop fully until late adolescence, presumably reflecting delayed maturation of the prefrontal cortex. ${ }^{24} 25$ While the saccadic inhibition deficit may be secondary to having a developmental social processing disorder, we hypothesise that it represents instead a late manifestation of neurodevelopmental dysfunction of the prefrontal cortex. We propose that deficits in executive function, and specifically inhibition, are present early in life and contribute to the development of social and behavioural problems in these syndromes. Studies using age appropriate measures are needed to establish the time course of these deficits and their relation to social and behavioural symptoms.

Deficits of saccadic inhibition are not specific to Asperger's disorder or SEPD. They are also found in several psychiatric disorders including schizophrenia. ${ }^{54}$ However, the saccadic inhibition deficit in Asperger's disorder may be qualitatively and quantitatively distinct. In contrast to schizophrenia, subjects with Asperger's disorder had normal latencies, amplitudes, and peak velocities for both prosaccades and antisaccades, ${ }^{55}$ and made one third fewer antisaccade errors. ${ }^{54}$ This suggests that Asperger's disorder is characterised by a more circumscribed and less severe saccadic inhibition deficit. Neuroimaging studies are necessary to characterise the distinct neural signatures of antisaccade deficits in these neurodevelopmental disorders.

The finding of intact task switching seems to contrast with clinical observations of perseverative behaviour in Asperger's disorder. It is important to note that task switching comprises several components and that the timing parameters for the current paradigm specifically tapped "residual" task switch costs. Studies of switching have suggested an early process of initiating a new task set that is triggered by an instructional cue and completed in 600-800 ms. ${ }^{56} 57$ Even with long cue lead times, some switching effects on latency and accuracy remain. These are termed residual switch costs, and may reflect residual influences of stimulus-response configurations from the previous trial. ${ }^{58}$ In addition, our paradigm measures task switching in relative isolation-it involves a fairly pure stimulus-response remapping. When studied in this manner, task switching is intact in Asperger's disorder and SEPD. The deficiency in Asperger's disorder responsible for perseverative behaviour may involve a closely related process, rather than the simple requirement to switch.

There are ongoing diagnostic controversies concerning the overlap and distinctiveness of Asperger's disorder and other developmental social processing disorders such as high functioning autism and SEPD. ${ }^{19} 212259$ We examined neurocognitive functions that are independent of diagnosis and found that the performance of individuals who met criteria for Asperger's disorder and SEPD could not be distinguished. Although the sample sizes were small, this inability to distinguish subgroups did not reflect a lack of power. The means for saccadic inhibition were quite similar, and each subgroup was significantly different from the control group. Perhaps this is not surprising given the considerable overlap in the criteria for these two disorders. The SEPD criteria used were consistent with our previous studies ${ }^{711} 1360$ and similar to those employed by other groups. ${ }^{12}{ }^{14-16}$ It is also noteworthy that many subjects met criteria for both Asperger's disorder and SEPD. The findings of indistinguishable saccadic performance and considerable overlap in diagnosis add to the debate about whether Asperger's disorder and SEPD are different disorders or the same disorder defined according to different nosological traditions. Determining whether there are valid distinctions between these diagnoses clearly requires further study with larger samples. Because all the subjects in the present study had been referred for neuropsychological evaluation, the sample may have been biased to greater neurocognitive impairment.

The study of Asperger's disorder and SEPD in late adolescence and in adults presents several challenges. Reports of early history and symptoms are necessarily retrospective, and parental informants are not consistently available. Moreover, the definition of Asperger's disorder is largely based on case studies of children, and most standard diagnostic instruments were developed for use with children and their parents. There is clearly a need for further development of standardised methods of assessment and diagnosis in older individuals with developmentally based social processing disorders. Adults with Asperger's disorder represent an underidentified and understudied group. Saccadic inhibition may be just one example of a deficit which, because of its late maturation, may only be apparent later in life. Longitudinal studies will be necessary to determine how the other cognitive deficits and symptoms that characterise Asperger's disorder evolve over the course of development.

\section{Conclusions}

Identifying intact and impaired neurocognitive function in developmental social processing disorders can guide investigations of neuropathology, clarify diagnosis, and reveal basic cognitive deficits that may contribute to symptom presentation. In this study we showed that both Asperger's disorder and SEPD are characterised by saccadic inhibition deficits and this is consistent with other evidence that implicates the prefrontal cortex.

\section{ACKNOWLEDGEMENTS}

We gratefully acknowledge the contributions of Matt Cain, James Intriligator, Mariya Cherkasova, and Elkan Halpern. Mary-Ellen Meadows, Aaron Nelson, Margaret O'Connor, and Cheryl Weinstein referred potential subjects and provided neuropsychological evaluations. We also thank our subjects and their families for their interest and participation. The study was supported by the National Institute of Mental Health (K23MH01829 (DSM)) and the National Institute of Neurological Disorders and Stroke (K08NS01920-01Al (JJSB)).

\section{Authors' affiliations}

D S Manoach, Department of Psychiatry and the Athinoula A Martinos Center for Biomedical Imaging, Massachusetts General Hospital, Harvard Medical School, Boston, Massachusetts, USA

K A Lindgren, Department of Psychiatry, Massachusetts General Hospital

J J S Barton, Department of Neurology, Beth Israel Deaconess Medical Center, Boston, Massachusetts

Competing interests: none declared

\section{REFERENCES}

1 Ozonoff S, Rogers SJ, Pennington BF. Asperger's syndrome: evidence of an empirical distinction from high-functioning autism. J Child Psychol Psychiatry 1991;32:1107-22.

2 Ozonoff S, Pennington BF, Rogers SJ. Executive function deficits in highfunctioning autistic individuals: relationship to theory of mind. J Child Psychol Psychiatry 1991;32:1081-105.

3 Rumsey JM. Conceptual problem-solving in highly verbal, nonretarded autistic men. J Autism Dev Disord 1985;15:23-36.

4 Morris RG, Rowe A, Fox N, et al. Spatial working memory in Asperger's syndrome and in patients with focal frontal and temporal lobe lesions. Brain Cogn 1999;41:9-26. 
5 Rumsey JM, Hamburger SD. Neuropsychological findings in high-functioning men with infantile autism, residual state. J Clin Exp Neuropsychol 1988;10:201-21

6 Hallett PE. Primary and secondary saccades to goals defined by instructions. Vision Res 1978;18:1279-96.

7 Manoach DS, Weintraub S, Daffner KR, et al. Deficient antisaccades in the social-emotional processing disorder. Neuroreport 1997;8:901-5.

8 Minshew NJ, Luna B, Sweeney JA. Oculomotor evidence for neocortical systems but not cerebellar dysfunction in autism. Neurology 1999;52:917-22.

9 Goldberg MC, Lasker AG, Zee DS, et al. Deficits in the initiation of eye movements in the absence of a visual target in adolescents with high functioning autism. Neuropsychologia 2002;40:2039-49.

10 Denckla MB. The neuropsychology of social-emotional learning disabilities [editorial]. Arch Neurol 1983;40:461-2.

11 Weintraub S, Mesulam MM. Developmental learning disabilities of the right hemisphere. Emotional, interpersonal, and cognitive components. Arch Neurol 1983;40:463-8.

12 Voeller KK. Right-hemisphere deficit syndrome in children. Am J Psychiatry 1986;143:1004-9.

13 Manoach DS, Sandson TA, Weintraub S. The developmental social-emotional processing disorder is associated with right hemisphere abnormalities. Neuropsychiatry Neuropsychol Behav Neurol 1995;8:99-105.

14 Rourke BP. Syndrome of nonverbal learning disabilities: the final common pathway of white-matter disease/dysfunction? Clin Neuropsychol 1987; 1:209-34.

15 Gross-Tsur V, Shalev RS, Manor O, et al. Developmental right-hemisphere syndrome: clinical spectrum of the nonverbal learning disability. J Learn Disabil 1995;28:80-6

16 Semrud-Clikeman M, Hynd GW. Right hemispheric dysfunction in nonverbal learning disabilities: social, academic, and adaptive functioning in adults and children. Psychol Bull 1990;107:196-209.

17 American Psychiatric Association. Diagnostic and statistical manual of mental disorders, 4th ed. Washington, DC: American Psychiatric Association, 1994

18 Grace J, Malloy P. Neuropsychiatric aspects of right hemisphere learning disability. Neuropsychiatry Neuropsychol Behav Neurol 1992;5:194-204.

19 Klin A, Volkmar FR, Sparrow SS, et al. Validity and neuropsychological characterization of Asperger syndrome: convergence with nonverbal learning disabilities syndrome. J Child Psychol Psychiatry 1995;36:1127-40.

20 McKelvey JR, Lambert R, Mottron L, et al. Right-hemisphere dysfunction in Asperger's syndrome. J Child Neurol 1995;10:310-14.

21 Miller JN, Ozonoff S. The external validity of Asperger disorder: lack of evidence from the domain of neuropsychology. $J$ Abnorm Psychol 2000;109:227-38.

22 Gunter HL, Ghaziuddin M, Ellis HD. Asperger syndrome: tests of right hemisphere functioning and interhemispheric communication. J Autism Dev Disord 2002;32:263-81

23 Voeller KKS. Social-emotional learning disabilities. Psychiatr Ann $1991 ; 21: 735-41$.

24 Munoz DP, Broughton JR, Goldring JE, et al. Age-related performance of human subjects on saccadic eye movement tasks. Exp Brain Res 1998; 121:391-400

25 Klein C, Foerster F. Development of prosaccade and antisaccade task performance in participants aged 6 to 26 years. Psychophysiology 2001;38:179-89.

26 Wechsler D. WAIS-III: Wechsler adult intelligence scale, 3rd ed. San Antonio: The Psychological Corporation, 1997.

27 White K, Ashton R. Handedness assessment inventory. Neuropsychologia $1976 ; 14: 261-4$.

28 Blair JR, Spreen O. Predicting premorbid IQ: a revision of the National Adult Reading Test. Clin Neuropsychologist 1989;3:129-36.

29 Hollingshead AB. Two factor index of social position. New Haven, Connecticut: Yale University Press, 1965.

30 Wechsler D. The Wechsler adult intelligence scale-revised. New York: Psychological Corporation, 1981.

31 Wechsler D. Wechsler memory scale-revised. San Antonio: The Psychological Corporation, 1987.

32 Wechsler D. Wechsler memory scale-third edition. San Antonio: The Psychological Corporation, 1997.

33 Warrington EK. Recognition memory test. Los Angeles: Western Psychological Services, 1984
34 Jastak S, Wilkinson G. The wide range achievement test-revised: administration manual. Wilmington: Jastak Associates, 1984.

35 Wilkinson GJ. The wide range achievement test-revision 3. Wilmington: Jastak Associates, 1993.

36 Benton AL, Van Allen MW. Impairment in facial recognition in patients with cerebral disease. Cortex 1968:4:344-58.

37 Benton AL, Hamsher K, Varney NR, et al. Contributions to neuropsychological assessment Oxford University Press, 1983.

38 Klove H. Clinical neuropsychology. Med Clin North Am 1963;47:1647-58.

39 Beck AT. BDI-II, Beck depression inventory: manual. San Antonio: The Psychological Corporation, 1996

40 Bahill T, McDonald J. Frequency limitations and optimal step size for the twopoint central difference derivative algorithm with applications to human eye movement data. IEEE Trans Biomed Eng 1983;30:191-4.

41 Sweeney JA, Mintun MA, Kwee S, et al. Positron emission tomography study of voluntary saccadic eye movements and spatial working memory. J Neurophysiol 1996;75:454-68

42 Doricchi F, Perani D, Inoccia C, et al. Neural control of fast-regular saccades and antisaccades: an investigation using positron emission tomography. Exp Brain Res 1997;1 16:50-62

43 Muri RM, Heid O, Nirkko C, et al. Functional organisation of saccades and antisaccades in the frontal lobe in humans: a study with echo planar functional magnetic resonance imaging. J Neurol Neurosurg Psychiatry 1998:65:374-7.

44 McDowell JE, Brown GG, Paulus $M$, et al. Neural correlates of refixation saccades and antisaccades in normal and schizophrenia subjects. Biol Psychiatry 2002;51:216-23.

45 O'Driscoll GA, Strakowski SM, Alpert NM, et al. Differences in cerebral activation during smooth pursuit and saccadic eye movements using positronemission tomography. Biol Psychiatry 1998;44:685-9.

46 Guitton D, Buchtel HA, Douglas RM. Frontal lobe lesions in man cause difficulties in suppressing reflexive glances and in generating goal-directed saccades. Exp Brain Res 1985;58:455-72.

47 Fukushima J, Fukushima K, Miyasaka K, et al. Voluntary control of saccadic eye movement in patients with frontal cortical lesions and parkinsonian patients in comparison with that in schizophrenics. Biol Psychiatry 1994;36:21-30.

48 Pierrot-Deseilligny C, Rivaud S, Gaymard B, et al. Cortical control of reflexive visually-guided saccades. Brain 1991;114:1473-85

49 Gaymard B, Ploner CJ, Rivaud-Pechoux S, et al. The frontal eye field is involved in spatial short-term memory but not in reflexive saccade inhibition. Exp Brain Res 1999:129:288-301.

50 Pierrot-Deseilligny C, Muri RM, Ploner CJ, et al. Decisional role of the dorsolateral prefrontal cortex in ocular motor behaviour. Brain 2003; 126:1460-73

51 Clementz BA, McDowell JE, Stewart SE. Timing and magnitude of frontal activity differentiates refixation and anti-saccade performance. Neuroreport $2001 ; 12: 1863-8$

52 Murphy DG, Critchley HD, Schmitz N, et al. Asperger syndrome: a proton magnetic resonance spectroscopy study of brain. Archives of General Psychiatry 2002; 59:885-91.

53 McAlonan GM, Daly E, Kumari V, et al. Brain anatomy and sensorimotor gating in Asperger's syndrome. Brain 2002;125:1594-606.

54 Manoach DS, Lindgren KA, Cherkasova MV, et al. Schizophrenic subjects show deficient inhibition but intact task switching on saccadic tasks. Biol Psychiatry 2002;51:816-25.

55 Ramchandran RS, Manoach DS, Cherkasova MV, et al. The relation of saccadic peak velocity to latency: evidence for a new prosaccadic abnormality in schizophrenia. Exp Brain Res (in press).

56 Allport A, Styles E, Hsieh S. Shifting intentional set: exploring the dynamic control of tasks. In: Umilta C, Moscovitch M, eds. Attention and performance. Hillsdale, NJ: Erlbaum, 1994:421-52.

57 Rogers RD, Monsell S. Costs of a predictable switch between simple cognitive tasks. J Exp Psychol 1995; 124:207-231.

58 Meiran N, Chorev Z, Sapir A. Component processes in task switching. Cogn Psychol 2000;41:211-53.

59 Volkmar FR, Klin A, Schultz RT, et al. Asperger's disorder. Am J Psychiatry 2000;157:262-7.

60 Sandson TA, Manoach DS, Price BH, et al. Right hemisphere learning disability associated with left hemisphere dysfunction: anomalous dominance and development. J Neurol Neurosurg Psychiatry 1994;57:1129-32. 